\title{
PARTICIPAÇÃO POLÍTICA DO PROFESSORADO DE EDUCAÇÃO FÍSICA NO MOVI- MENTO SINDICAL
}

\author{
PARTICIPACIÓN POLÍTICA DEL PROFESORADO DE EDUCACIÓN FÍSICA EN EL \\ MOVIMIENTO SINDICAL
}

\section{POLITICAL PARTICIPATION OF THE PHYSICAL EDUCATION TEACHER IN THE TRADE UNION MOVEMENT}

DOI: http://dx.doi.org/10.9771/gmed.v11i3.34466

\author{
Giovanni Felipe Ernst Frizzo ${ }^{1}$ \\ Leonardo Lemos Silveira ${ }^{2}$ \\ Ivan Bremm de Oliveira ${ }^{3}$
}

Resumo: Este artigo tem por objetivo analisar a participação política do professorado de Educação Física (EF) no movimento sindical. A partir de uma perspectiva crítico-dialética, tendo como base teórica a concepção ontológica de trabalho, utilizamos um questionário com perguntas abertas e fechadas intitulado Enquete Docente com 26 docentes de EF de 18 escolas da Rede Estadual de Ensino em Pelotas-RS. Com os resultados, foi possível compreender que a formação inicial e as desigualdades de gênero são importantes elementos para a não participação política no movimento sindical. Também identificou-se que um pouco mais da metade do professorado de EF não tem envolvimento político com as atividades do sindicato que os representa.

Palavras-chave: Educação Física; Participação Política; Escola Pública

Resúmen: Este artículo tiene como objetivo analizar la participación política de los maestros de Educación Física (EF) en el movimiento sindical. Desde una perspectiva dialéctica crítica, basada en la concepción ontológica del trabajo como base teórica, utilizamos un cuestionario con preguntas abiertas y cerradas titulado Encuesta de docentes con 26 docentes de educación física de 18 escuelas de la Red Estatal de Enseñanza en Pelotas-RS. Con los resultados, fue posible comprender que la capacitación inicial y las desigualdades de género son elementos importantes para la no participación política en el movimiento sindical. También se encontró que un poco más de la mitad de los maestros de educación física no tienen participación política en las actividades del sindicato que los representa.

Palabras clave: Profesores. Educación Física. Política. Educación Secundaria

Abstract: This article aims to analyze the political participation of Physical Education teachers (PE) in the union movement. From a critical-dialectic perspective, based on the ontological conception of work as a theoretical basis, we used a questionnaire with open and closed questions entitled Teacher Survey with 26 PE teachers from 18 schools in the State Teaching Network in Pelotas-RS. With the results, it was possible to understand that initial training and gender inequalities are important elements for the political non-participation in the union movement. It was also found that a little more than half of PE teachers have no political involvement in the activities of the union that represents them.

Keywords: Teachers. Physical Education. Politics. Education Secondary

\section{Introdução}


No desenvolvimento da pesquisa "Educação Física, Mudanças do Mundo do Trabalho e a Reforma Curricular do Ensino Médio", integrante dos estudos do Grupo de Pesquisa Organização do Trabalho Pedagógico da Educação Física (OTPEF), utilizamos como instrumento de coleta de informações um questionário, com perguntas abertas e fechadas, intitulado Enquete Docente que foi respondido por docentes de Educação Física (EF) que atuam no Ensino Médio (EM) da Rede Pública Estadual do Rio Grande do Sul (RS) na cidade de Pelotas-RS. Este instrumento foi dividido em 6 seções: trabalho e formação; condições de trabalho docente; saúde e qualidade de vida; organização do trabalho pedagógico; engajamento político; questões gerais. Com base na penúltima seção da Enquete Docente, fizemos um cruzamento de informações de dados pessoais respondidos e outros aspectos relevantes para este artigo que tem por objetivo analisar a participação política do professorado de EF no movimento sindical.

A restruturação produtiva e as transformações no mundo do trabalho das últimas décadas, especialmente originadas pela maior interação entre meios tecnológicos e a esfera de produção, tem sido acompanhadas também de mudanças de paradigmas na formação escolar. Exemplo destas modificações é a construção da Base Nacional Comum Curricular (BNCC) em curso que pretende estabelecer parâmetros de formação articulada nacionalmente e também a recente aprovação da Reforma do Ensino Médio que aprofunda a concepção mercadológica para a formação escolar. Tais processos de mudanças no currículo do Ensino Médio (EM) tem tido ressonância na rede estadual de ensino do RS. Ainda no ano de 2011, o Governo do Estado divulgou um documento-base que intitulou "Proposta Pedagógica para o Ensino Médio Politécnico e Educação Profissional Integrada ao Ensino Médio - 2011-2014”, tratou-se de uma proposta de reestruturação curricular do EM para "desenvolver um projeto educacional que atenda às necessidades do mundo do trabalho, mas que tenha na sua centralidade o indivíduo, a partir de uma proposta de formação integral” (RIO GRANDE DO SUL, 2011, p.8).

Desde a implantação do Ensino Médio Politécnico no RS surgiram diversas dúvidas por parte do professorado e estudantes perante a nova estrutura curricular. A proposta trouxe certa insegurança por apresentar uma série de dificuldades em sua implementação que se iniciou em 2012. Diante disto, emergiu a importância e a necessidade de pesquisar e compreender as relações entre as mudanças do mundo do trabalho e a organização do trabalho pedagógico no EM Politécnico no RS, tendo como lócus de investigação as escolas estaduais do município de Pelotas-RS.

Para desenvolver tal investigação, definiu-se como central a análise da realidade do trabalho docente e pedagógico nas escolas estaduais partindo dos conceitos da categoria trabalho. A categoria ontológica do trabalho, como atividade humana produtiva da existência, e sua dimensão histórica, manifestada a partir da relação entre capital e trabalho, constitui-se um conjunto de relações que configuram o Mundo do Trabalho, originando um campo investigativo que supera por incorporação as análises centradas exclusivamente nas relações do mercado de trabalho. Isto é, há uma considerável limitação em pensar as relações de trabalho docente somente na esfera do mercado, pois este se configura como um espaço de compra e venda da mercadoria força de trabalho, mercadoria esta que é propriedade do trabalhador nas relações de assalariamento. Portanto, o limite se estabelece a partir da constatação de 
que o trabalho é produtor da própria existência do ser humano, mediação deste com a natureza e com os demais homens e mulheres, não podendo ser reduzido à uma mercadoria (embora no sistema sóciometabólico atual, esta atividade humana é subsumida ao capital e tornada meio de produção de capital).

Ao apontar o trabalho enquanto categoria fundante do ser social e de sua centralidade no desenvolvimento da sociedade, onde os diferentes modelos de produção até então experimentados pela humanidade estabelecem as bases para a reprodução de sua forma de organização, buscamos entender os fundamentos da formação humana e como esta se manifesta no atual período histórico. De maneira geral, a educação se consolida na incumbência de atender as demandas apresentadas pela esfera produtiva, formando um determinado tipo de ser humano necessário à lógica do mercado.

Nosso ponto de partida é o trabalho compreendido como mediação de primeira ordem no processo de produção da existência e objetivação da vida humana. A dimensão ontológica do trabalho é, assim, o ponto de partida para a produção de conhecimento e de cultura pela humanidade. No entanto, a produção da existência adquire caráter histórico relativo ao modo de produção em que a existência é produzida. O trabalho docente, portanto, é uma prática social que expressa, dentro das suas possibilidades objetivas, as determinações políticas e ideológicas dominantes em uma sociedade ou, por contradição, busca a explicitação da superação destas determinações. Como particularidade da forma trabalho, o trabalho docente estabelece relações distintas de outras possibilidades quando o produto da atividade é consumido no ato de produção, diferente do trabalho de um operário na fábrica, por exemplo. Na forma de assalariamento própria do sistema do capital, também o trabalho docente se distingue do trabalho produtivo que produz diretamente mais-valia, pois a caracterização do professorado vinculado ao serviço público não estabelece centralmente a produção de lucratividade ou mais-valia como elemento basilar de sua atividade.

Ao mesmo tempo, o trabalho docente também se relaciona com a forma mercadoria na medida em que sua produção: a) é diretamente realizada pelas instituições de ensino superior, através dos cursos de licenciatura que, por sua vez, são regulados e regulamentados pelos órgãos e instâncias governamentais do sistema nacional de ensino; b) a prioridade de formação profissional em detrimento da formação humana no Ensino Superior brasileiro que, segundo Filippini (2013), coadunam com o projeto impetrado pelo capital à educação no que tange à gestão e os processos decisórios, bem como da subsunção da formação às demandas do mercado de trabalho. Ou seja, há uma implicação significativa da concepção geral de formação inicial na realização do trabalho do professorado na escola, bem como em seu engajamento nas atividades políticas de sua própria categoria profissional.

E, ainda, como afirmou Silva e Molina Neto (2012, p. 870), "há uma multiplicidade de determinaçoões da prática social, das relações familiares e da formação inicial que se sintetizam e contribuem para a formação politica de professores de Educação Física".

A estrutura sindical brasileira passou por diversos processos para sua atual configuração. A partir da década de 1930, a existência de sindicatos foram regulamentadas e tornaram-se oficiais e vinculados à esfera da administração federal, isto é, os sindicatos, federações e centrais sindicais devem ser 
reconhecidas pelo Ministério do Trabalho e Emprego para terem suas atividades regularizadas. Foi somente após o fim da ditadura empresarial-militar e o processo constituinte que culminou na Constituição Federal de 1988, que os servidores públicos puderam se organizar em sindicatos, o que até então estava proibido.

A reestruturação produtiva levada a cabo a partir dos anos 1990 no Brasil, de corte neoliberal, implicou em mudanças significativas na atuação e organização do movimento sindical. As mudanças na legislação trabalhista, ampliação das formas de terceirização, do trabalho temporário, da personalidade jurídica de empregados e as múltiplas formas de organização empresarial trouxeram consigo uma importante ramificação da produção e das empresas, o que culminou com um significativo enfraquecimento dos sindicatos em relação à representatividade de sindicalização dentre as bases de trabalhadores e trabalhadoras.

$\mathrm{Na}$ atualidade, a proporção de trabalhadores filiados aos sindicatos de suas categorias, no país, é limitada a 16,2\%, o que corresponde a 17,3 milhões de pessoas. No serviço público, a taxa de sindicalização é de 36,8\% dos servidores. Em comparação com outros países, os maiores percentuais de trabalhadores e trabalhadoras sindicalizadas é da China 42\%, Itália 37,3\% e Argentina 30,4\%; enquanto os países que têm a menor taxa de sindicalização é o Peru 1,8\%, Turquia 6,3\% e Indonésia 7\% (CAMPOS, 2016).

Em relação ao magistério estadual do RS, a entidade sindical que representa a categoria dos trabalhadores em educação (professorado e funcionários de escola) é o Centro dos Professores do Estado do Rio Grande do Sul - Sindicato dos Trabalhadores em Educação (CPERS-Sindicato), fundado em 1945 como Centro de Professores que tinha um perfil associativista embora com envolvimento nas pautas de reivindicações da categoria. O CPERS-Sindicato é transformado oficialmente em sindicato no ano de 1989, após a promulgação da Constituição Federal.

\section{Metodologia}

Esta investigação tem por base o materialismo histórico dialético, definido a partir da realidade concreta do trabalho docente em que se analisam as condições nas quais este se desenvolve, articulado à estrutura do modo de produção capitalista que modificou substancialmente os fundamentos da produção da existência humana através do trabalho assalariado que, dentre outros aspectos, concebe o trabalho enquanto mercadoria - força de trabalho. Neste processo, se desenvolve um grau de alienação que coloca a esfera ontológica do trabalho subsumida à lógica histórica do trabalho sob as diretrizes do capital.

A Enquete Docente foi respondida por docentes de EF das escolas estaduais da cidade de Pelotas-RS que trabalham ou trabalharam no EM desde o ano de implementação da nova proposta curricular em 2011. A definição de participação do professorado que atua no EM nesta pesquisa é decorrente do fato de que a incumbência da oferta do EM é prioridade dos Estados e, no RS, as últimas administrações estaduais tem dimunuído a oferta de matrículas e fechado escolas de Ensino Fundamental em razão da prioridade desta oferta ser de responsabilidade dos municípios. Portanto, a etapa da 
Educação Básica em que se encontram a ampla maioria do professorado da rede estadual é nas escolas de EM. Assim como, para este artigo que trata da participação política no movimento sindical é significativa a colaboração de docentes da base do CPERS-Sindicato, pois este é um dos maiores sindicatos da América Latina de trabalhadores da educação, com aproximadamente 80 mil docentes e trabalhadores sindicalizados, com uma trajetória de 73 anos de atividade sindical.

Com este recorte, participaram da pesquisa 26 docentes que atuam em 18 escolas estaduais de EM da cidade de Pelotas-RS de um total de 23 escolas existentes no âmbito da $5^{a}$ Coordenadoria Regional de Ensino ( $\left.5^{\mathrm{a}} \mathrm{CRE}\right)$ do RS, sendo 20 localizadas na Zona Urbana e 03 na Zona Rural. Destas escolas, uma não tem EF por se tratar de uma escola de nível técnico profissionalizante em nível subsequente e as 4 escolas restantes não tivemos retorno do questionário ou foi negada a participação pelo professorado.

Consideramos que os resultados são significativos pelo percentual de participação de docentes, totalizando $82 \%$ de escolas envolvidas (excetuando a escola que não oferta EF em seu currículo), sendo 15 de Zona Urbana e 3 de Zona Rural, portanto com uma abrangência relevante para os objetivos propostos. Em relação ao número de participantes, é difícil identificar o número total de docentes que atuam no EM em virtude da rotatividade elevada existente na rede estadual, tanto no sentido de ingresso e exoneração de professores e professoras quanto no âmbito de atuação dos docentes (alguns docentes trabalham no Ensino Fundamental em determinados momentos e depois no EM em outros). Desta forma, fizeram parte da investigação o número máximo de docentes que responderam à Enquete Docente, sem eliminação de nenhum questionário. Todos os participantes do estudo assinaram um Termo de Consentimento Livre e Esclarecido para que suas informações pudessem ser utilizadas na compilação das informações coletadas e passaram por análise estatística e de conteúdo, portanto, sendo analisadas através de métodos quantitativos e qualitativos, os quais constituíram as categorias empíricas da pesquisa.

O professorado de EF da Rede Estadual de Ensino, na cidade de Pelotas, que atua no EM é composto em sua maioria por mulheres (65\%), casadas (46\%), com filhos $(69 \%)$ e com pequena prevalência de idade entre 31 a 40 anos (31\%). Destaca-se ainda o baixo percentual de docentes com idade até 30 anos (12\%), período em que se tem maior prevalência do término do curso de formação inicial de professores de EF. Possivelmente, o baixo número de docentes com esta faixa etária na rede estadual se deva pelos vários anos em que não houve concurso público para a Rede Estadual de Ensino, portanto, os docentes que compõem a categoria já ingressaram há mais tempo e já tem idade acima de 30 anos.

\section{Envolvimento do professorado no movimento sindical}

Uma das categorias de respostas à Enquete Docente se referiu à questão de engajamento político. Ou seja, a relação que cada docente de EF no EM tem com as ações políticas da categoria docente, seja em relação ao seu sindicato como suas iniciativas pessoais.

Ao serem perguntados sobre a participação em manifestações, greves e atos políticos, $50 \%$ respondeu que se envolvem em tais atividades, enquanto $42 \%$ respondeu não participar; $8 \%$ respondeu que participa às vezes. Para além da participação, a metade do professorado envolvida nas ações políticas 
justifica com elementos sobre a necessidade da luta para a conquista de direitos, especialmente a defesa da educação pública. Tais como apresentados pelos seguintes fragmentos de respostas: "Porque acho importante lutar por uma educação de qualidade e respeito ao servidor" (Resposta do Professor 15); "acredito que é a única forma de manifestar nossa insatisfação com o governo que trata de forma desrespeitosa nossa categoria, já que não chama para o diálogo, é através da greve. Não existe evolução sem luta" (Resposta do Professor 17).

Uma parte importante dos docentes (42\%) não tem se envolvido com as ações políticas da categoria, por um lado em decorrência da descrença ou desesperança de que a situação possa mudar através das lutas políticas e, por outro lado, respostas que apontam para a dificuldade de participar de ações políticas em decorrência de tarefas domésticas, falta de dinheiro ou por conta de jornadas de trabalho em outras redes de ensino. Segundo Zibetti e Pereira (2010, p. 265), "a docência tem sido caracterizada com uma profissão extremamente desgastante, cuja execução é agravada pelas condições de trabalho tais como jornadas exaustivas, salários insuficientes e demandas que extrapolam o ambiente profissional.

Em relação à vinculação a organizações políticas, sindicatos e movimentos sociais, um pouco mais da metade dos entrevistados (54\%) não são sindicalizados no CPERS-Sindicato. Para além do sindicato, também temos três docentes (14\%) que são filiados a partidos políticos e 1 professor sindicalizado por outra categoria profissional. O total de docentes sindicalizados no CPERS-Sindicato é de $46 \%$. Embora aproximadamente a metade do professorado participante da pesquisa seja sindicalizado no CPERS-Sindicato, apenas 35\% participa das assembleias e demais atividades do sindicato; e a ampla maioria do professorado de EF não tem se caracterizado por participar da gestão do sindicato, apenas $8 \%$ dos colaboradores já tiveram esta experiência ao longo de sua carreira profissional.

Também são bastante divididas as opiniões do professorado em relação ao que pensam sobre o sindicato e sua importância para a categoria docente. As manifestações positivas sobre a avaliação da relação do sindicato com o professorado é de $42 \%$, enquanto as negativas somam $46 \%$; não responderam ou não sabiam, $12 \%$. Importante relacionar com as respostas anteriores de que somente a metade dos docentes são sindicalizados e, portanto, tem vínculo orgânico com a entidade. É possível afirmar que estes dados positivos e negativos estejam relacionados com o fato de serem sindicalizados ou não.

As manifestações positivas se referem à atuação e compreensão do sindicato como o espaço de construção das lutas e conquistas da categoria. Tais como os seguintes fragmentos: "Tudo que conseguimos tem a ver com a luta da classe reunida, sozinhos não conseguimos nada" (Resposta do Professor 4); “É a forma de unirmos nossas forças e enfrentarmos esses governos autoritários” (Resposta do Professor 18).

Enquanto as manifestações negativas referem-se mais diretamente às gestões do sindicato em que apontam-se críticas no sentido da vinculação política dos dirigentes sindicais à pautas que extrapolam os interesses da categoria, tais como expressos na seguinte resposta: "Não vejo nenhuma relação custobenefícios. São pessoas filiadas a determinado partido político agindo como cabos eleitorais" (Resposta do Professor 14). 
Um aspecto interessante encontrado nas respostas é que alguns docentes demonstraram-se preocupados com as dificuldades enfrentadas na conjuntura política da atualidade e que se desdobra no sentido que o sindicato tem para a categoria, como podemos observar nos seguintes trechos:

Na minha opinião é elementar, é através do sindicato que os professores conseguem ter acesso ao governo e reivindicar seus direitos. Mas, eu sei de muitos professores que não acreditam na licitude do sindicato e estão desacreditados na luta (Resposta do Professor 25).

Outras respostas apontam: "bastante preocupado com as questões, mas sem força devido aos constantes ataques do governo e retaliações” (Resposta do Professor 10); “o Sindicato somos todos nós, não adianta dizer: ‘o Cpers não faz nada'. E o que nós fazemos?” (Resposta do Professor 20).

Ao buscarmos compreender as determinações sobre o não envolvimento do professorado de EF nas atividades do sindicato ou mesmo pelas razões de não serem filiados, fizemos um cruzamento de informações que permitiram apontar elementos de compreensão acerca desse fenômeno, conforme apontamos abaixo.

\section{Participação política e formação inicial}

As instituições de ensino superior que ofertam cursos de licenciatura em Educação Física e formam o professorado que atua nas escolas da Educação Básica estabelecem a sua estrutura curricular e projeto pedagógico com base nas Diretrizes Curriculares Nacionais (DCN) para sua respectiva área de conhecimento e também das diretrizes gerais de formação de professores em cursos de licenciatura. Ressalta-se que estamos vivenciando uma recente modificação de DCN para os cursos de licenciatura através da Resolução CNE/CP 2/2015 (BRASIL, 2015), porém ainda prevalecem as determinações mais gerais da formação inicial estabelecidas pela Resolução CNE/CP 1/2002 (BRASIL, 2002).

Ao longo do tempo, diversas modificações e novas DCN foram aprovadas e modificaram o sentido e a formação inicial de professores de EF. No quadro abaixo é possível verificar uma síntese das mudanças curriculares da EF ao longo dos anos, conforme Taffarel (2010).

Quadro 1: Reformulações Curriculares da Educação Física

\begin{tabular}{|c|c|c|c|}
\hline Ano & Decreto/Resolução & Modalidade & Duração do curso \\
\hline 1939 & Decreto-Lei 1212/39 & Licenciatura em Educação Física & 02 anos \\
\hline 1945 & Decreto-Lei 8270/45 & Licenciatura em Educação Física & 03 anos \\
1969 & Resolução CFE/69 & Licenciatura em EF e Técnico Desportivo & 03 anos \\
1987 & Resolução 03/CFE/87 & Licenciatura e/ou Bacharelado em EF & 04 anos \\
\hline 2004 & $\begin{array}{c}\text { Resolução } \\
07 / C N E / 04\end{array}$ & Graduado em Educação Física & 04 anos \\
\hline
\end{tabular}

Fonte: Taffarel (2010) 
Em que pese o caráter técnico-instrumental que balizam as DCN, as instituições de ensino podem desenvolver processos formativos que contemplem aspectos mais gerais de formação, incluindo questões relativas à formação política, artística, cultural, ética, filosófica etc. Porém, nas últimas décadas, em decorrência das orientações de organismos internacionais e demandas internas de restruturação produtiva, se observa que o projeto de formação de professores vincula-se à concepções restritas ao caráter profissional vinculado à esfera de mercado de trabalho.

Em relação às atuais DCN da EF, constata-se que:

O projeto de formação que se baseia [...] a Resolução CNE/CES 07/2004 advém de determinações impostas pelos organismos internacionais (BIRD, FMI, UNESCO) para as politicas educacionais aos paises em desenvolvimento, ou seja, imposiçoes de organizações externas até mesmo às instâncias decisórias da política educacional brasileira (FILIPPINI, 2013, p. 73)

A fragmentação da formação em EF, oriunda das mudanças curriculares que estabeleceram a divisão em cursos de Licenciatura e Bacharelado, incorreram também na restrição de acesso à totalidade de conhecimentos da área, vinculando-se às demandas de mercado e intervenção profissional. Tal fato tem sido analisado de forma crítica, como aponta Filippini (2013) ao afirmar que os conhecimentos necessários para desenvolver uma atitude crítica, para compreender e analisar as relações sociais, o mundo do trabalho, desenvolver uma teoria pedagógica alternativa não estão sendo tratados ao longo da formação dos professores de Educação Física em ambas as habilitações. Além disso, o currículo de graduação é esvaziado em relação a questões políticas (OST, 2010), prioriza-se então, o aspecto técnico-instrumental que vai ao encontro do que é imposto pelos marcos regulatórios da EF.

Ainda sobre as críticas à fragmentação da formação inicial, Both (2009, p. 97) estabelece uma relação entre a realidade de precarização da formação com os movimentos mais gerais do capital e da restruturação produtiva decorrente da atual crise sistêmica.

A formação que vem sendo realizada nos cursos de graduação em Educação Física atende aos interesses do capital, pois ao invés do debate centrar-se no aspecto epistemológico, ou seja, colocar como centro da discussão o objeto central da Educação Física ser a docência, independente do local de atuação, e então ver como se poderia estruturar o currículo com vistas ao trabalhador da área compreender e trabalhar nos diferentes campos de atuação, o debate é realizado a partir da necessidade da formação de um trabalhador para atuar num dito novo mercado de trabalho, cindindo tanto o conhecimento a ser produzido e socializado, bem como, dificultando uma compreensão sob a perspectiva da totalidade por parte dos trabalhadores da área.

Ao analisarmos as respostas do professorado, identificamos que o período em que cada docente realizou a sua formação superior tem significativa determinação em seu engajamento político no movimento sindical. Pois, $60 \%$ dos docentes que não participam de manifestações e greves da categoria terminaram sua graduação após as mudanças curriculares que fragmentaram a formação e restringiram o acesso ao conhecimento da área. Assim como, $54 \%$ dos docentes que não são sindicalizados também encerraram a sua formação inicial neste período. O quadro 2 expressa a relação entre a Formação Inicial (FI) e a participação política do professorado entre docentes que não tem envolvimento com o sindicato.

Quadro 2: relação entre Formação Inicial (FI) e participação política 


\begin{tabular}{|c|c|c|c|}
\hline & $\begin{array}{c}\text { FI a partir dos anos } \\
2000 \\
(\mathrm{~N} \mathrm{e} \%)\end{array}$ & $\begin{array}{c}\text { FI antes dos anos } 2000 \\
(\mathrm{~N} \mathrm{e} \mathrm{\% )}\end{array}$ & $\begin{array}{l}\text { TOTAL* } \\
(\mathrm{N} \text { e } \%)\end{array}$ \\
\hline $\begin{array}{l}\text { Não participa de manifesta- } \\
\text { ções e greves** }\end{array}$ & $6-60 \%$ & $4-40 \%$ & $10-100 \%$ \\
\hline $\begin{array}{l}\text { Não é sindicalizado no } \\
\text { CPERS-Sindicato }\end{array}$ & $7-54 \%$ & $6-46 \%$ & $13-100 \%$ \\
\hline $\begin{array}{c}\text { Participa de manifestações } \\
\text { e greves }\end{array}$ & $5-38 \%$ & $8-62 \%$ & $13-100 \%$ \\
\hline $\begin{array}{c}\text { É sindicalizado no CPERS- } \\
\text { Sindicato }\end{array}$ & $5-42 \%$ & $7-58 \%$ & $12-100 \%$ \\
\hline
\end{tabular}

Fonte: dados da pesquisa

*uma das colaboradoras do estudo não informou a data de sua FI

** dois docentes informaram participar "as vezes" das atividades, não foram incluídos na tabela

Por estes dados apresentados, também é possível verificar que a maior parte do professorado que é sindicalizado no CPERS-Sindicato é formada antes dos anos 2000, portanto tiveram suas formações iniciais durante as mudanças mais recentes das DCN para formação de professores em cursos de licenciatura e também das DCN para a EF.

Outro aspecto acerca da formação inicial que chama atenção nos resultados é que, dentre os docentes que colaboraram com o estudo, 3 professores fizeram sua graduação em faculdades privadas e a totalidade destes docentes não participa de manifestações e greves; não são sindicalizados e não participam de assembleias da categoria. Ou seja, embora um número considerado baixo de amostra, há uma tendência de distanciamento de envolvimento político do professorado formado também nas instituições privadas de ensino.

\section{Participação política de professoras}

Ao analisarmos os resultados da Enquete Docente no que diz respeito à participação política do professorado de EF no movimento sindical, a representatividade de gênero teve significativos resultados. De acordo com Ferreira (2004), no início dos anos 2000 o número de sindicalizados no CPERS-Sindicato era de 82.560 . Destes, $88,3 \%$ eram mulheres e $11,7 \%$ homens. Neste estudo, como pode ser observado no Quadro 3, de 26 participantes $46 \%$ são sindicalizados, sendo 67\% dos homens que responderam o questionário e $35 \%$ das mulheres. Significa que 33\% dos professores não são sindicalizados no CPERSSindicato e $65 \%$ das professoras não são sindicalizadas.

Através destes dados, identificamos que há uma diferença importante entre a participação política do professorado de EF de demais docentes do magistério público estadual, na medida em que a grande maioria de docentes sindicalizadas são professoras mulheres, enquanto que do professorado de EF a maioria de sindicalizados é composta por professores homens.

Além destas questões, o quadro 3 também apresenta as informações gerais acerca das respostas do professorado em relação a seu envolvimento político e diferenças entre gênero. Pelos dados, é possível identificar uma sensível diferença de gênero na participação de manifestações e greves da categoria 
docente, na qual as mulheres apresentam participação menor (47\%) que homens (33\%), com base na totalidade da amostra.

\begin{tabular}{|c|c|c|c|}
\hline \multicolumn{1}{c|}{ Quadro 3: relação entre gênero e participação política } & $\begin{array}{c}\text { TOTAL } \\
\text { (N e \%) }\end{array}$ \\
\hline $\begin{array}{c}\text { Homens } \\
\mathbf{( N ~ e ~ \% )}\end{array}$ & $\begin{array}{c}\text { Mulheres } \\
\mathbf{( N ~ e ~ \% ) ~}\end{array}$ & $11-42 \%$ \\
\hline $\begin{array}{c}\text { çõos e greves } \\
\text { Não é sindicalizado no } \\
\text { CPERS-Sindicato }\end{array}$ & $3-33 \%$ & $8-47 \%$ & $14-54 \%$ \\
\hline Total amostra & $3-33 \%$ & $11-65 \%$ & $26-100 \%$ \\
\hline
\end{tabular}

Fonte: dados da pesquisa

De acordo com Leone e Teixeira (2010), mesmo com o contínuo crescimento da inserção da mulher no mercado de trabalho e no movimento sindical, ainda persistem grandes dificuldades para lograrem uma inserção apropriada, pois ainda continuam a se reproduzir práticas discriminatórias e excludentes no movimento sindical.

A discussão sobre gênero e participação política se torna ainda mais relevante quando temos de acordo com dados do Tribunal Superior Eleitoral (TSE, 2018) em nível nacional mais da metade do eleitorado pertencente ao gênero feminino (54,78\%), em nível de RS, 52,46\% e em nível municipal da pesquisa (Pelotas) o mesmo índice nacional (54,78\%).

É possível afirmar que a extensão de jornada de trabalho para além da atividade profissional como o cuidado dos filhos/marido/familiares e do trabalho doméstico, que na sociedade patriarcal são comumente responsabilizados para as mulheres, acabam por dificultar a participação das professoras em ações políticas, especialmente sindicais. De acordo com as autoras supra-citadas, "o desafio de superar a exclusão das mulheres da vida sindical passa por uma reflexão mais ampla sobre o papel da divisão sexual do trabalho, que define tarefas distintas e estabelece papéis rígidos para homens e mulheres" (LEONE; TEIXEIRA, 2010, p. 20)

Sendo a participação política um direito/dever de todos de acordo com a Constituição Federal, não basta apenas os documentos oficiais informarem desse direito/dever, devem assegurar condições políticas e possibilidades econômicas e sociais para que as pessoas possam efetivamente gozar do direito a vida política, até porque, historicamente a política foi “[...] construída como um espaço masculino. O esquema mental que fazia com que a esfera pública fosse vista como estranha às mulheres, também fundava os mecanismos estruturais de exclusão que impediam o acesso delas a esta esfera" (MIGUEL, 2011, p.141).

E isso, talvez explique a ausência de mulheres nesses espaços democráticos e de poder do nosso país. Além da mulher possuir múltiplas funções diárias, o preconceito histórico fez com que não se reconheçam como pertencente à determinados ambientes.

\section{Considerações Finais}


O desenvolvimento desta investigação alcançou dados sobre a realidade do trabalho docente da EF no EM na Rede Estadual de Ensino do RS, na cidade de Pelotas, que permite uma considerável compreensão acerca dos elementos que constituem o fazer docente, tanto no sentido das dificuldades como também dos desafios que a carreira profissional atravessa ao longo de sua trajetória.

Ao relacionarmos a concepção ontológica de trabalho, a categoria docente e o envolvimento dos mesmos na organização sindical, por meio da interpretação marxista identificamos que em relação ao engajamento político da categoria, os resultados foram bastante divididos: metade do professorado é sindicalizada e participa de uma forma ou de outra das lutas da categoria, enquanto a outra metade não é sindicalizada e não se envolve (por diferentes razões) nas decisões coletivas da categoria.

Assim, os docentes sindicalizados percebem em suas ações um papel político crítico como uma das formas de saída da situação de precarização e intensificação do trabalho docente. Nesse sentido, podemos dizer que os mesmos identificam na luta coletiva e organizada através do movimento sindical, inspirada na unificação das forças e na constatação do processo sócio-histórico uma forma de enfrentamento e superação do quadro instaurado, sendo esse o caminho para uma prática profissional que compreenda melhor os desafios que se fizeram e se fazem presentes.

Dentre o professorado que não se envolve ou participa dos espaços políticos de sua categoria, especificamente aqui no movimento sindical, foi possível encontrar duas tendências importantes para compreensão desse achado:

1) As restruturações curriculares oriundas de mudanças sociais e orientações de organismos internacionais impactam diretamente na participação política do professorado. Docentes que formaram-se a partir dos anos 2000, período em que se intensificam as políticas educacionais de corte neoliberal, tem menor envolvimento com o movimento sindical, seja na participação em manifestações e greves, ou mesmo sindicalizados em sua entidade representativa. Destaca-se ainda que, do professorado que colaborou com a investigação, três docentes fizeram sua formação inicial em instituições privadas e a totalidade destes não são engajados em atividades sindicais e não são sindicalizados. Em que pese ser uma pequena amostra, nos parece necessário projetar estudos que busquem compreender este fenômeno com mais profundidade.

2) Identificou-se também que há uma disparidade de gênero significativa no engajamento político do professorado no movimento sindical. Pois, entre os homens a maior parte destes participam de greves e manifestações ou são sindicalizados; enquanto que a maioria das mulheres não se envolvem com as atividades do movimento sindical e não são sindicalizadas. Isso pode ser explicado pelos fundamentos da sociedade patriarcal em que as mulheres realizam múltiplas tarefas no cotidiano, o que as afastaria do movimento sindical.

Nessa direção, podemos dizer que os baixos salários que levam a situação de multiempregos e a uma elevada carga horária, além da descrença em mudanças concretas, a dupla jornada laboral e familiar no caso das professoras, além da reestruturação curricular dos cursos de formação inicial, esvaziado de questões políticas e de caráter instrumental, atuam como barreiras impeditivas e limitam a atuação do professorado na participação e no engajamento político através do sindicato de sua classe. Cremos na 
necessidade de transcender o modo de produção vigente que atende somente aos interesses do capital, a partir de uma perspectiva histórico-crítica, transgressora das leis gerais de reprodução do capital, elegendo o ser humano como base principal do processo produtivo. Pois é necessário romper com a lógica desse sistema movido pelo capital se quisermos contemplarmos uma alternativa eduiacional significativamente diferente (MÉZÁROS, 2008).

Por fim, o desenvolvimento dessa coleta de dados e decorrente investigação científica trouxe significativos resultados. A utilização da Enquete Docente permitiu a participação de um expressivo número de docentes que atuam no EM da Rede Estadual de Ensino do RS na cidade de Pelotas-RS e pode servir para futuras investigações em outras redes de ensino ou em outros municípios, buscando verificar as tendências e dissonâncias entre os resultados a que chegamos.

\section{Referências}

BRASIL. Conselho Nacional de Educação/Conselho Pleno. Resolução n.01, de 18 de fevereiro de 2002. Conselho Nacional de Educação/Conselho Pleno. Resolução n.02, de 1 de julho de 2015.

BOTH, Vilmar. Mudanças no mundo do trabalho e suas mediações na Educação Física. 2009. Dissertação (Mestrado). Universidade Federal de Pelotas, Pelotas, 2009.

CAMPOS, André Gambier. Sindicatos no Brasil: o que esperar no futuro próximo? Texto para Discussão, Rio de Janeiro: IPEA, 2016

FERREIRA, Márcia. Mulheres e Homens em Sindicato Docente: um estudo de caso. Cadernos de Pesquisa, vol. 24, n. 122, p. 391-410, mai/ago 2004.

FILLIPPINI, Isabella. A Organização do Trabalho Pedagógico e o Trato com o Conbecimento na Formação de Professores de Educação Física. 2013. Dissertação (Mestrado). Universidade Federal de Pelotas, Pelotas, 2013.

LEONE, Eugenia; TEIXEIRA, Marilane. As mulheres no Mercado de Trabalho e na Organização Sindical. In: XVII Encontro Nacional de Estudos Populacionais. Anais... Caxambu-MG, 20 a 24 de setembro de 2010.

MÉSZÁROS, István, 1930- A educação para além do capital / Isteván Mészarós ; [tradução Isa Tavares]. -2. ed. - São Paulo: Boitempo, 2008. 125 p. - (Mundo do trabalho).

MIGUEL, Luis Felipe. Mulheres e espaços de poder no Brasil. Autonomia econômica e empoderamento da mulher: textos acadêmicos. Brasília: Fund. A. de Gusmão, p. 139-155, 2011.

OST, M. A. Formação Continuada em Educação Física: um estudo sobre as propostas da Secretaria de Educação e Desporto da Prefeitura Municipal de Pelotas-RS. 2012. Dissertação (Mestrado). Universidade Federal de Pelotas, Pelotas, 2012.

SILVA, Guilherme Gil da; MOLINA NETO, Vicente. Um estudo sobre Formação Política de Professores de Educação Física. Revista Brasileira de Ciências do Esporte, Florianópolis, v. 34, n. 4, p. 859-873, out./dez. 2012.

TAFFAREL, Celi. Do Trabalho em Geral ao Trabalho Pedagógico: contribuição ao debate sobre trabalho pedagógico na Educação Física. Motrivivência, n. 35, p 18-40, dez/2010.

TRIBUNAL SUPERIOR ELEITORAL. Estatísticas do eleitorado 2018. Disponível em:< www.tse.jus.br/eleitor-e-eleicoes/estatisticas/estatisticas-de-eleitorado/estatistica-do-eleitorado-por-sexoe-faixa-etaria>. Acesso em: 28 abr. 2018.

ZIBETTI, Maria Lúcia; PEREIRA, Sidnéia. Mulheres e professoras: repercussões da dupla jornada nas condições de vida e no trabalho docente. Educar em Revista. Número Especial 2, 2010, p. 259-276. 


\section{Notas:}

${ }^{1}$ Escola Superior de Educação Física da Universidade Federal de Pelotas. Professor Adjunto. Professor Adjunto da Escola Superior de Educação Física da Universidade Federal de Pelotas. Doutor em Ciências do Movimento Humano pela UFRGS. Formado em Licenciatura Plena em Educação Física pela Universidade Federal do Rio Grande do Sul (UFRGS). Tem experiência na área de Educação Física, atuando principalmente nos seguintes temas: formação de professores, trabalho e educação, trabalho pedagógico, escola e mundo do trabalho. ORCID: http://orcid.org/0000-0003-0025-9947 Email: gfrizzo2@gmail.com

${ }^{2}$ Doutorando em Educação Física pela Universidade Federal de Pelotas no Programa de Pós-Graduação em Educação Física (UFPel/PPGEF). Doutorando em Educação Física pela Universidade Federal de Pelotas no Programa de Pós-Graduação em Educação Física (UFPel/PPGEF) na área de concentração Movimento Humano, Educação e Sociedade, linha de pesquisa: Formação Profissional e Prática Pedagógica. Mestre em Educação Física (UFPel/PPGEF) na área de concentração Movimento Humano, Educação e Sociedade, linha de pesquisa: Formação Profissional e Prática Pedagógica, é Especialista em educação pelo Instituto Federal Sul-Rio-Grandense (IFsul) e Licenciado em Educação Física pela Escola Superior de Educação Física (UFPel/ESEF). Pesquisando sobre os seguintes temas: trabalho pedagógico, pobreza e educação, desigualdade social, precarização do trabalho docente. Atualmente é integrante do grupo de estudos: Organização do Trabalho Pedagógico da Educação Física da UFPel/ESEF e do grupo Educação Física e Opressões: a Cultura Corporal no combate à descriminação (UFPel/ESEF). ORCID: http://orcid.org/0000-0003-3982-4069 Email: 1lsleonardolemossilveira@gmail.com

3 Doutorando em Educação Física pelo Programa de Pós-Graduação em Educação Física (PPGEF/UFPel). Escola Superior de Educação Física- ESEF. Doutorando em Educação Física pelo Programa de Pós-Graduação em Educação Física (PPGEF/UFPel) na linha de Pesquisa Formação Profissional e Prática Pedagógica. Possui Licenciatura em Educação Física (2011-2015), Mestrado em Educação Física (2015-2017), Especialização em Educação Física Escolar pela (2017-2018) ambos pela ESEF/UFPel. Foi bolsista do Programa Institucional de Bolsa de Iniciação a Docência PIBID/CAPES, além de ser árbitro de Atletismo (FAERGS/CBAt) e Técnico Administrativo em Educação- Assistente em Administração do Instituto Federal de Educação, Ciência e Tecnologia Sul-Rio-Grandense (IFSul), Campus Pelotas lotado na Coordenadoria de Educação Física. Membro Grupo de Pesquisa em Organização do Trabalho Pedagógico (GPOTPEF/ESEF/UFPEL)), do Grupo de Pesquisa em Educação Física e Educação (GPEFE/ESEF/UFPEL) e Grupo de Estudos em Educação Física, Esporte e Lazer (GRUPEL/ESEF/UFPEL). Atua principalmente nos seguintes temas: formação de professores e professoras, trabalho e educação, trabalho pedagógico, escola e mundo do trabalho, carreira docente, Produção do conhecimento em Educação Física. ORCID: http://orcid.org/0000-0002-2601-8714 Email: ivanbremmoliveira@gmail.com 